\title{
A New System for Evaluating a Siberian City: Evaluation Methodology
}

\author{
Alena Stupina ${ }^{1, *}$, Olga Shagaeva ${ }^{2}$, Sergey Yamaletdinov $^{3}$, Oleslav Antamoshkin $^{4}$, Roman Kuzmich $^{1}$, \\ Irina Ruiga ${ }^{1}$ \\ ${ }^{1}$ Institute of Business Process Management, Siberian Federal University, Krasnoyarsk, 660074, Russia \\ ${ }^{2}$ Institute for the Humanities, Siberian Federal University, Krasnoyarsk, 660041, Russia \\ ${ }^{3}$ Institut of Architecture and Design, Siberian Federal University, Krasnoyarsk, 660041, Russia \\ ${ }^{4}$ Institute of Space and Information Technologies, Siberian Federal University, Krasnoyarsk, 660074, Russia
}

Received April 19, 2021; Revised June 7, 2021; Accepted July 19, 2021

\section{Cite This Paper in the following Citation Styles}

(a): [1] Alena Stupina, Olga Shagaeva, Sergey Yamaletdinov, Oleslav Antamoshkin, Roman Kuzmich, Irina Ruiga, "A New System for Evaluating a Siberian City: Evaluation Methodology," Civil Engineering and Architecture, Vol. 9, No. 5, pp. 1318 - 1326, 2021. DOI: 10.13189/cea.2021.090505.

(b): Alena Stupina, Olga Shagaeva, Sergey Yamaletdinov, Oleslav Antamoshkin, Roman Kuzmich, Irina Ruiga (2021). A New System for Evaluating a Siberian City: Evaluation Methodology. Civil Engineering and Architecture, 9(5), 1318 1326. DOI: 10.13189/cea.2021.090505.

Copyright $\bigcirc 2021$ by authors, all rights reserved. Authors agree that this article remains permanently open access under the terms of the Creative Commons Attribution License 4.0 International License

\begin{abstract}
The aim of this work is the creation of a universal evaluation system, suitable for different types of buildings to conduct a comprehensive expert analysis of the residential environment on the example of the city of Krasnoyarsk. Today, there are several basic groups of qualities of the residential environment: technical, economic, geographical and esthetic, each of which is an independent direction of urban construction. Despite their connection, each individual group cannot be considered in isolation from other factors to obtain a complete picture for the state of the living space. The main problem in this case is a competent interrelated evaluation of these groups of criteria, determining the most significant of them for each type of construction. The research methodology is based on the study of residential complexes, the survey of specialists, the analysis of residential complexes characteristics, the comparative evaluating approaches and methods for evaluating the residential environment, the data obtained, and the analysis of literary sources. The research suggests the consideration of the residential environment in two stages: mathematical and cross-scale. As a result, we get an evaluation system that is suitable for different types of construction in the Krasnoyarsk Region, and in the future, in other regions.
\end{abstract}

Keywords PREQ, Residential Environment, Krasnoyarsk, Residential Complex, Evaluation

\section{Introduction}

Today, there is no system of criteria for evaluating the residential environment that could be equally applied in all localities of the Siberian region. The existing systems for evaluating the modern residential environment either cover some blocks of parameters, ignoring others, which prevents a comprehensive analysis, or are not fully applicable due to the Siberian specifics.

A lot of foreign and Russian studies are devoted to the issues of qualitative evaluating the residential environment, affecting various aspects of the development and formation of residential environment in the city.

Consider the Russian experience of evaluating residential spaces. One of the most important works for this study is the work of R. G. Arakelyan "Improving the quality of the residential environment considering the values of traditional residential formations (on the example of the territory of the Armenian Highlands)" [1] in which the author uses mathematical formulas to describe such concepts as the harmonization of building dimensions, determining the accessibility level of a residential unit, its identity, recognition. Attention is drawn to the monograph "Innovative economy and 
management in the modern world", authored by I. Ya. Lvovich, A. P. Preobrazhensky, O. N. Choporov, A. I. Rybak, made within the framework of the SWorld project [2]. However, the accuracy of obtaining the data required under the evaluation system mentioned above is questionable.

The next block of works is represented by the studies of I. V. Matveeva and T. N. Lunina [3], A.V. Dementiev and V. Yu. Domozhilov [4], and M. V. Paskhina [5], Kuzmin A.V., Yusin G. S., [6], Kuleshov G. I., Sergeev K. I. [7], where the expression of the estimated means of the residential environment occurs with the help of technical and economic indicators of the territory, as well as their compliance with urban planning regulations. The works of Grishina A. and Shilkin N. V., as well as Bakaeva N. V., Natarova A. Yu., Igin A. Yu. are interesting, they consider retinated residential environments with the help of the new regulatory documentation National Association of Builders (NABUILD) 2.35.4-2011 "Green building" [8], [9]. An attempt to develop a unified system of criteria for assessing the residential environment of Moscow was made by Argunov S. V. and Kogan Yu. V. [10].

The final block of Russian works consists of a few studies that present a ready-made methodology for rating the residential environment, as well as its typification and the search for possible scenarios for the development of the territory. These include the "Standard of complex territories development", created by the architectural bureau "Strelka" and the Institute "Urbanistic" [11], which is aimed more at creating possible scenarios for the development of the residential environment space, as well as the "Quality rating of the residential environment. Rating methodology" of the University "Urbanistic" and the University of Information Technologies, Mechanics and Optics (ITMO), the Institute of Design and Urban Studies [12], which considers exclusively new high-rise buildings in St. Petersburg.

In the studies of some foreign scientists, much attention is also paid to the quality of the urban environment and its evaluation. Some scientists, like Ya. Gale, as well as Nafeth Naser Alddeen, focus mainly on issues of human perception of the city, without paying enough attention to the engineering or economic aspects of the urban environment quality [13], [14]. Other researchers only pay attention to the ecological or energy-saving characteristics of the urban environment, or evaluate only the quality of housing in the context of urban construction. At the moment, the most well-known evaluating the residential environment quality abroad is Perceived Residential Environment Quality (PREQ).This system and its variations are considered in detail in the works of such prominent foreign scientists as Fornara F., Bonaiuto M., Bonnes M. in the works "Cross-Validation of Abbreviated Perceived Residential Environment Quality (PREQ) and Neighborhood Attachment (NA) Indicators" [15], and "Indexes of Perceived Residential Environment Quality and Neighborhood Attachment in Urban Environments: a Confirmation Study on the City of Rome"[16], as well as Bonaiuto M., Fornara F., Ariccio S., Cancellieri U. G., Rahimi L. in the paper "Perceived Residential Environment Quality Indicators (PREQIs) Relevance for UN-HABITAT. City Prosperity Index (CPI)"[17].The PREQ rating system is based on a survey of residents on 362 parameters, which helps to assess their vision of the residential environment comfort. The system affects not only the points about how satisfied people are with the living space, its landscaping and urban construction, but also the vision of people regarding communication within this space. For example, in PREQ there is a block of evaluating the residential environment "People and social relations", which raises the questions of how often people in your area gossip, whether people have only formal relations with neighbors, whether people often communicate with neighbors, whether a person feels that he is being watched, etc. [15]. Such an evaluation, in our opinion, cannot always give a clear picture of the urban construction situation in a particular area. This is because the answers are strongly subjective, often the respondents cannot qualitatively justify why they find buildings in their area unattractive, and the PREQ rating scale proposed in the work "Indexes of Perceived Residential Environment Quality and Neighborhood Attachment in Urban Environments: A Confirmation Study on the City of Rome" [16] and consisting of seven points, does not imply a detailed answer. In addition, it is doubtful whether such a system can be applied in the conditions of the Russian region, where the community of neighbors is still far from the European level. The question arises, is it possible to assess the neighbors community of a small low-rise complex and a high-rise residential complex in the same way?

The second most popular scale for evaluating the quality of the residential environment abroad is represented by the Neighborhood Attachment (NA) scale. A detailed review of this evaluation system is presented in the work "Indexes of Perceived Residential Environment Quality and Neighborhood Attachment in Urban Environments: A Confirmation Study on the City of Rome" [16]. The system consists of 16 points, which also assume the answers of the district residents to the questions raised. The proposed methodology involves a survey of residents regarding the maintenance state of the area infrastructure. However, the absence of boundary values for the questions asked in this scale raises questions. For example, there are no boundaries about whether a person feels that people in their area do not respect their surroundings (buildings, district, area), whether a person feels that there are too many empty spaces in the streets of the area. For one respondent, the concept of "too much" will be equivalent to 5, for another-200, which will undoubtedly make it much more difficult to process the data and get a clear result. 
Also, a block of works concerning the socio-cultural, economic and political factors that can influence the typology of the historical cities development is of interest. A detailed consideration of such patterns is presented in the work "Socio-economic and Geo-political Transitions in the Mediterranean Basin and Its Impact on Urban Forms of Port Cities" [18].

\section{Materials and Methods}

The research methodology is based on a full-scale survey of residential complexes in the city of Krasnoyarsk, an expert survey, an analysis of qualitative characteristics, a comparative evaluating the data obtained, and an analysis of literary sources.

There are two main levels of residential environment spaces: personal and public spaces, which differ in the level of social communication. In order to address both levels of the residential environment, the basic unit of this study was adopted as a residential complex, as a self-sufficient unit of the planning structure for a modern city, in which all the necessary structural elements are present to determine the qualities of the residential environment of the city.

As part of this work, we selected 56 residential complexes of the city, located in different administrative districts. All the selected territories differ in the type of construction, planning principle, transport accessibility, style and number of floors. Such a variety of localities will help to get detailed results for the state of the city's residential environment. The selected residential complexes are shown in figure 1 .

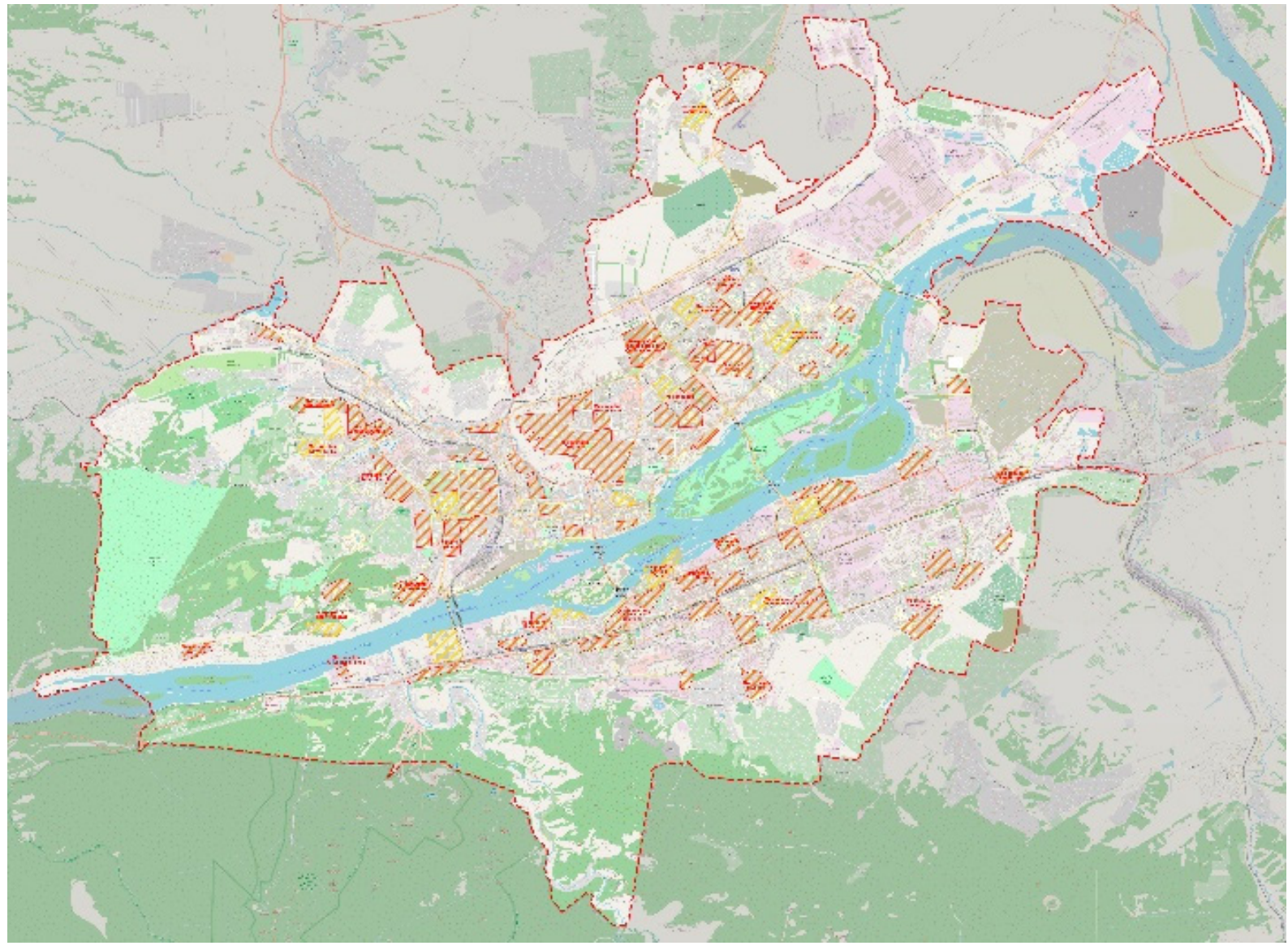

Figure 1. The studied territories in the structure of Krasnoyarsk 
The field survey method was performed by us in GIS systems (2GIS, OpenStreetMap), helping to obtain clear field data on six blocks of parameters:

- building typology parameters (1 parameter);

- basic technical and economic parameters (8 parameters);

- basic stylistic parameters (5 parameters);

- transport and pedestrian accessibility parameters (4 parameters);

- psychological parameters (parameters of human perception of space) (7 parameters);

- parameters of the residential complex infrastructure.

It is worth noting that the full-scale method in this study is used to obtain only the initial data, which does not represent the final evaluation. These materials are necessary for the final clear evaluation, calculation of the coefficient and obtaining other data that are part of the final report.

The expert survey method is used to determine the quality of the residential environment in detail. Experts are people who have secondary specialized and higher education in the field of architecture and urban planning. To exclude the subjective component, 12 of the 56 residential complexes of the city were selected, which were evaluated simultaneously by 3 experts. In addition, in order to obtain accurate results, six blocks of territory evaluation were developed based on the type of its construction; the limit values of the territory evaluation according to one or another principle are indicated, detailed explanations are given regarding the area scoring.

\section{Results}

A comprehensive analysis of the residential environment of Krasnoyarsk was carried out in 2 stages, based on the approaches to obtaining results mathematical and cross-scale. The first stage helps to get dry data used for a clear analysis of the existing qualities of the city's residential environment, its spatial, economic and esthetic characteristics. The second stage, cross-scale, at the same time helps to give a much more detailed evaluation of the comfort level for the residential environment based on clearly defined environmental parameters. In the second stage, an expert analysis of the studied territories is carried out in order to obtain a score rating for a particular parameter of the studied territory. Look at each of the stages in more detail:

\subsection{The Mathematical Stage}

A distinctive feature of the first stage is to obtain accurate data by accurately measuring the study area. For the convenience of further consideration, all the data of the mathematical stage were conditionally divided into six groups, the data from which were responsible for a specific criterion for the development of the studied territory. Consider the mathematical data for groups:

1. The territory typology parameter is the initial research criterion. It involves determining the type of a microdistrict construction for further evaluation and identifying the qualities that are most significant for each of the selected zones. The system of building typologies adopted by researchers and Russian legislation [6] was chosen as the most universal system for determining the basic characteristics of the development of microdistricts in the urban environment. According to the above-mentioned ranking system, all considered residential complexes can be divided into five conditional groups based on the type of construction: individual urban environment, medium-rise microdistrict urban environment, multi-storey microdistrict urban environment, Soviet perimeter urban environment, historically mixed urban environment. The researchers also gave a definition of what each group represents, along with generalized characteristics, such as number of floors, density of buildings, and the quality of road and street stock. Based on a certain typology, the necessary basic characteristics and possible scenarios for further development are selected. You can get acquainted with the stylistic and compositional trends in the development of Krasnoyarsk neighborhoods in the article [19].

2. A group of basic technical and economic parameters. Such a block of materials includes the total area of a residential complex, the ground part area of the green spaces' structures, highways within the studied territory, the number of floors, the number of residents, and the density of the housing stock. The data included in the group of this block is the base for all further studies for the area of any residential complex. They help to make a conclusion about the greening of the area, transport and pedestrian permeability, the required volume of basic social services (a school for a certain number of places, the number of parking spaces, etc.), will help to monitor compliance with urban planning standards (insolation and fire protection standards), and are also a starting point for considering the esthetic component of the territory.

3. Basic stylistic parameters. At this stage, the existing stylistic qualities of such residential complexes are determined, which make it possible to determine the esthetic environmental component. The above type of criteria includes stylistics, the type of landscaping (spontaneous or organized), the presence of architectural and planning techniques for organizing space, accent and standard elements, a single-color solution for the space of residential complexes.

4. Parameters of transport and pedestrian accessibility of residential complexes. They mean the distance in kilometers to the nearest public transport stop, the 
public center of the territory and the city center, as well as the development parameter of the transport and pedestrian network.

5. Psychological parameters, represented by the difference in height, width, length and distance between the buildings of a residential complex, the typologies number of residential buildings, the total number of courtyards and the difference in their areas. The data is a starting point for determining the identity degree of the living space, the accessibility coefficient, calculating the humane height, the length of buildings that can be integrated into the existing building, calculating the comfortable proportions of new buildings that lie in the visual field of a person, the humane dimensions of the courtyard space. Studies describing the harmonization and humane dimensions of the living space using mathematical formulas of linear dependence were taken as a basis, when working with this block of parameters [1].

- The degree of identity of the living space is defined as the ability of a person to identify their housing, as well as to classify themselves as belonging to a particular community, which makes it possible to meet the needs for security, belonging, recognition, prestige, etc. To determine the degree of identity, a model is used that expresses this coefficient through a system of linear dependence "K[D] $\rightarrow \mathbf{K}[\mathbf{A}] \rightarrow \mathbf{K}[\mathbf{T}]$ ", which describes the quantitative ratio of the system of yard spaces, addresses (residential buildings) and typologies of residential units. As a result, the final formula for the identity of the residential environment was proposed

$$
I \%=\frac{K_{i} * 100 \%}{2,2} .
$$

- Humane dimensions of buildings are defined as psychologically comfortable, human-perceived proportions of the building, equivalent to the geometry of the visual fields of view. Based on the comfortable angle of view in the vertical projection, equal to an average of $27^{\circ}$, the psychologically comfortable height of the building is calculated by the formula:

$$
H=I \operatorname{tg} 27^{\circ}+L,
$$

where $H$ is the height of the building;

$\operatorname{tg} 27^{\circ}(0,50952)$ is a comfortable angle of view in a vertical projection above the horizon;

$I$ is the interval from the outline of the building to the observer's axis, or to the outline of the opposite building;

$L$ is the level of the horizon (the height from the ground to the eye level of the observer-1500 mm).

The planimetric dimensions of the building lying in the visual field of a person are calculated in an identical way:

$$
A=2\left(\operatorname{Itg} 30^{\circ}\right),
$$

where $A$ is the width of the building;

$\operatorname{tg} 30^{\circ}(0,57735)$ is half of the comfortable viewing angle in the horizontal projection;

I is half of the comfortable viewing angle in the horizontal projection.

- The accessibility coefficient of a residential unit as a concept is quite new, but the meaning contained in this indicator is one of the fundamental factors in the design of a residential environment. It is responsible for how quickly and easily a person can get through the public space of the street and the semi-private space of the courtyard to their home. There is a high and low degree of accessibility, depending on the planning structure of the building. In order to mathematically determine the degree of accessibility, researchers are invited to refer to the laws of network organization and describe the plan of an existing object using cells and links. As the researchers emphasize, such a technique "helps to graphically and analytically identify the structural patterns of spontaneous organization of residential environment, as well as to determine the degree of accessibility and the control degree of a particular residential unit, describing the structure of the "grid" of residential environment with the help of "cells" and "connections" between these cells" [1]. The entrance to the building is taken as a cell, and the number of paths to this cell is taken as a link. To identify the numerical equivalent for the availability degree of an element from a branch-like structure, the availability coefficient $\mathrm{K}_{\mathrm{d}}$ is introduced, calculated using the Hanson and Hiller formula.

$$
K_{d}=\frac{1 K+2 K_{2}+\cdots n K_{n}}{m-1},
$$

where $K_{d}$ is an indicator of the element's status in the general system;

$n$ is the ordinal number of the most remote level;

$1 K, 2 K, \mathrm{n} K$ is the number of vertices, locums on each of the levels;

$m$ is the total number of vertices.

- Humane dimensions of the courtyard space. According to scientific research, a person perceives the courtyard space through the geometric ratio of the height of the opposite residential units and the interval between them. At the same time, if the correct dimensions of the internal space for the residential courtyard are not observed, disharmony occurs. The researchers describe the existing problem as follows: "In modern urban planning practice, especially in panel residential buildings, an interval exceeding the sum 
of the visual fields of the opposite buildings is characteristic. At the same time, the space between the buildings itself, in view of the inefficient use of the territory, the lack of developed landscaping, the poverty of spatial forms, is devoid of a sufficient number of visible elements. One of the ways to compensate for the destructive space is the intensive organization of green zones. Dense green spaces will significantly increase the number of visible elements by filling in the courtyard void, create a new geometry and silhouette of the courtyard space, as well as increase the environmental friendliness of the residential environment" [1]. To determine the mathematical relationship between the dimensions of the building and the perception of a person, the perimeter of the courtyard space is used - the figure $\mathrm{ABCD}$ and the height of two opposite buildings V1 and V2. You can get acquainted with the humanization of space in Krasnoyarsk for more information in [20].

Not so long ago, architects were the first to mathematically determine the relationship between the distances between opposite buildings in space and their heights. According to it, if the interval is twice the sum of the visual fields $(\mathbf{A B C D}>\mathbf{V 1}+\mathbf{V} \mathbf{2} \rightarrow \mathbf{1 : 8})$, formed by buildings, then there is an "empty", structureless space. In this case, the observer no longer feels any interaction between the buildings. Comfortable conditions of psychological and visual perception are achieved in the case of geometric equality of the interval between buildings and the sum of visual fields $(\mathbf{A B C D}=\mathbf{V} \mathbf{1}+\mathbf{V} \mathbf{2}$ $\rightarrow \mathbf{1 : 4}$ ). If the size of the interval corresponds to the size of the visual field, then there is a limit interval of comfortable visibility $(\mathbf{A B C D}=\mathbf{V 1}, \mathbf{V} \mathbf{2} \rightarrow \mathbf{1 : 2})$. The feeling of cramped space occurs if the interval corresponds to half the size of the visual field $(\mathbf{A B C D}<$ $\mathbf{V} 1, \mathbf{V} 2 \rightarrow 1: 1)$ [1].

6. Parameters of the residential complex infrastructure. Compliance of the existing infrastructure elements of the studied territory with the required volumes, level of service, as well as service radium. The requirements of SP 42.13330.2016 "Urban construction. Planning and construction of urban and rural territories" were taken as the basis for these measurements.

It is worth noting that the parameters presented in the above-mentioned blocks of criteria have the same meaning as the PREQ and NA evaluation systems. At the same time, the key difference lies in the method of obtaining data for further evaluation. Foreign systems for evaluating the residential environment receive materials about the architectural, spatial and esthetic qualities of the area by interviewing residents, while this study involves obtaining the same data in terms of meaning by using GIS systems, coupled with the field method and further mathematical processing. The final data, at the stage of information output, thus get a complete view and can be ranked according to the requirements of Russian or foreign legislation in the field of urban planning and construction of residential territories (habitable territory). Using the obtained data, the parameters for human perception of space can be determined by using numerical materials in the proven linear dependencies mentioned in block 5. All the tools described above significantly improve the accuracy of the evaluating the residential environment. Based on the data obtained, we can also perform a comparative analysis of the territories for each of the studied principles. Examples of the results obtained are shown in fig. 2-4.

Based on the results of the first stage, we get primary, indisputable data on the quality of residential environment for the urban area. However, such data is not sufficient to fully understand the current state of the study area. Illustrating the above, a short walking route is not fully an indicator of the modern residential environment, at the moment there are certain requirements for the quality of this route, an important role is played by how exactly a person will overcome this route - along an untidy, low-quality narrow gravel path or along a wide alley lined with beautiful paving stones, admiring the landscaping, flower beds. It is to obtain additional data that cannot be obtained mathematically that the second, CROSS-SCALE STAGE was introduced into this study.

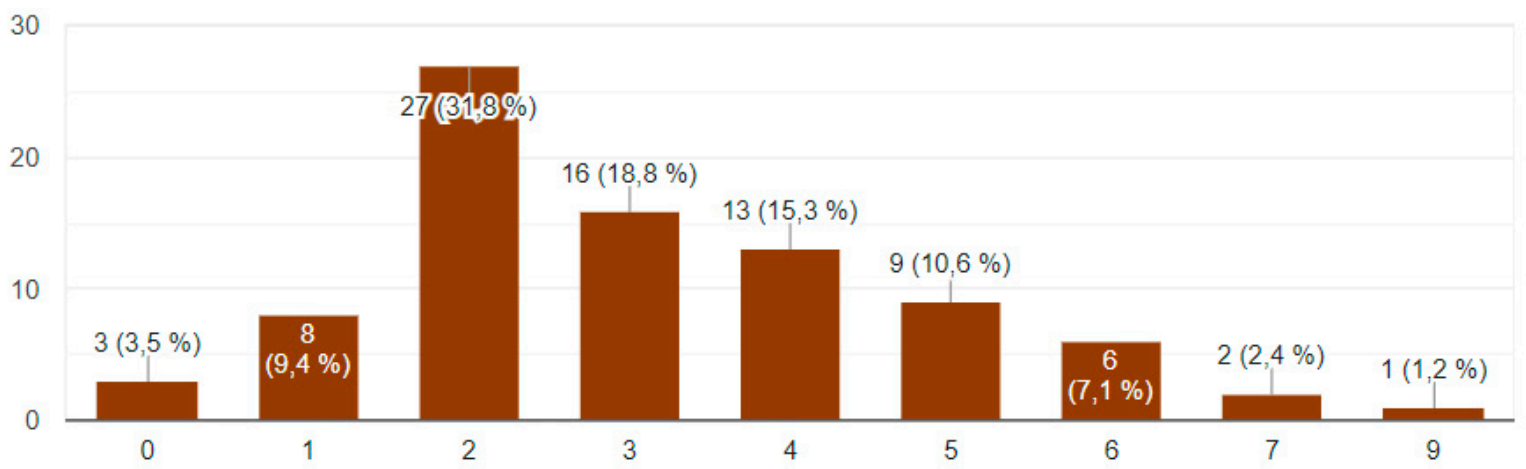

Figure 2. Comparative analysis of the equipment of the considered territories with bus stops 


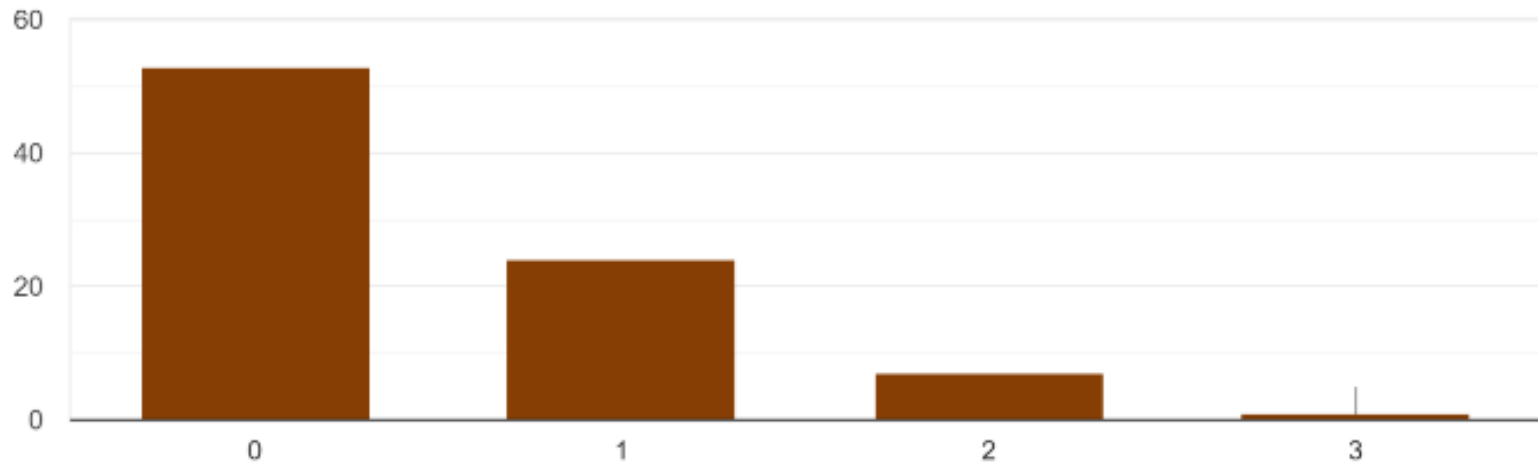

Figure 3. Comparative analysis of the equipment of the considered territories with parks and squares

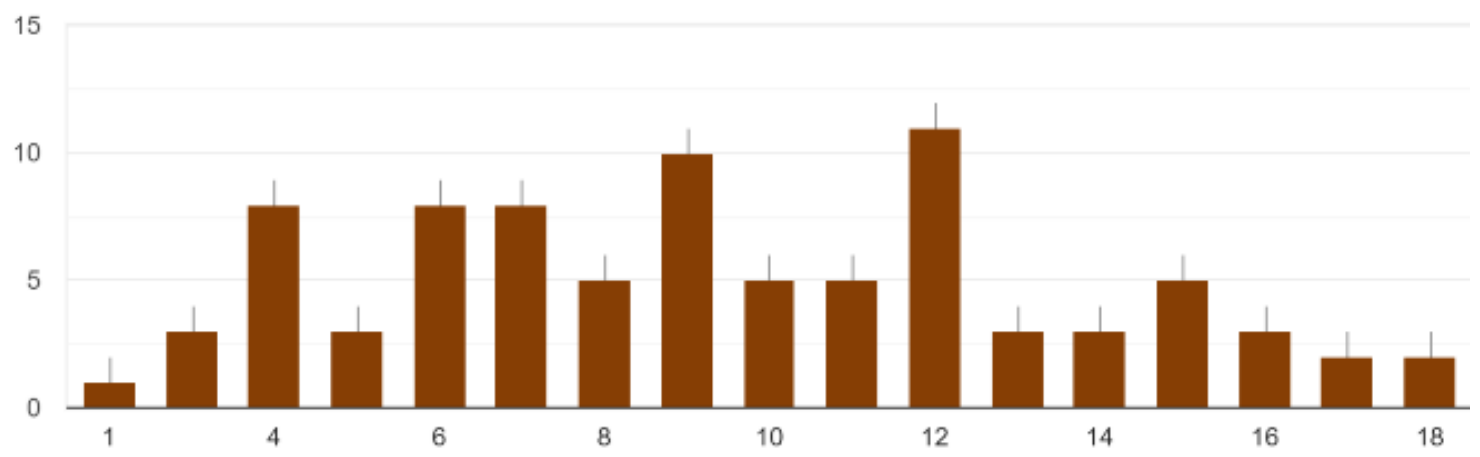

Figure 4. Comparative analysis of the equipment of the considered territories with grocery stores

\subsection{Cross-Scale Stage}

The cross-scale method implies the consideration of residential units through the prism of several urban planning scales: city-residential complex-quarter-yard, which helps to get the most detailed picture for the residential environment state of the studied territory. We have adopted the rating system as the most accurate for determining the results obtained. The developed rating methodology was used to compile the rating table [7]. At the same time, we made significant changes due to the fact that the mentioned methodology was developed for a relatively new, multi-storey construction in St. Petersburg. In order to apply the rating system, we changed the rating scale to consider the different types of buildings and planning solutions of the studied residential complexes. To illustrate the above, a low-rise urban construction cannot be characterized by the same accessibility type of infrastructure services as a multi-storey micro district urban environment.

Within the framework of the cross-scale stage, the following groups of parameters were considered:

The scale of the city:

1. Sociotype of the territory. It is understood as the proximity to the studied territory of objects that affect the safety and comfort of the residential complex, reducing the quality of its social environment, and, as a result, its consumer attractiveness.
The scale of the residential complex:

1. Infrastructure parameters (class definition of social infrastructure represented in the residential complex, quality and variety of commercial and social functions of the study area).

2. Parameters of the transport and road network. This includes both the time to the basic infrastructure services, and the quality of the pedestrian route to them, the using the latest methods of organizing the transport and road network of the residential complex (high-quality storage organization of personal and guest vehicles, priority of pedestrian traffic, the absence of through passages through courtyards, high-quality road surface).

3. Landscaping parameters presented in the studied territory.

The scale of the yard:

1. Esthetic parameters (the quality of the architectural and stylistic solution of the facade, the quality of landscaping, the type of landscaping).

In order to get as accurate data as possible, explanations were added to the survey questionnaire regarding scoring: for which parameters the studied area receives a certain number of points. Extremely accurate descriptions for various classes of commercial and social real estate and elements of external improvement of the residential complex territory were added to the questionnaire, and 
examples of characteristics that reduce the sociotype of the territory were given.

As a result of the cross-scale stage we received the missing data on the quality and characteristics of the existing urban environment.

\section{Discussion and Conclusions}

Today, there are several blocks of Russian and foreign works that offer their own systems for evaluating the quality of the residential environment. Many of them evaluate one or more groups of parameters. The most popular system for determining the comfort of a residential environment abroad is PREQ and NA. However, there are doubts about whether it is possible to apply this methodology in the realities of the Russian region, with its climatic features, parameters of architectural and socio-cultural construction. This study proposes a methodology that helps to obtain more accurate data than PREQ and NA due to the fact that the tool for evaluating the residential environment is not a survey of residents who do not have sufficient competence for an accurate evaluation, but a full-scale method using GIS systems. It becomes possible to obtain a comparative assessment of the estimated territories for each of the parameters. An example of a comparative analysis can be seen in figures 5 and 6 . Thanks to this, we can clearly see all the existing shortcomings of each of the considered territories for taking appropriate urban planning measures.

The auxiliary method is the method of expert analysis with regulated scoring for each of the points and, at the same time, for each of the five types of territory development. As a result, we received a fund of evaluation tools for the quality of the residential environment for different types of development. The overall result of the work is the creation of a new system for evaluating residential environment, which not only helps to give an accurate evaluation of the current state of the residential environment, but also to indicate the limit values of parameters for new development.

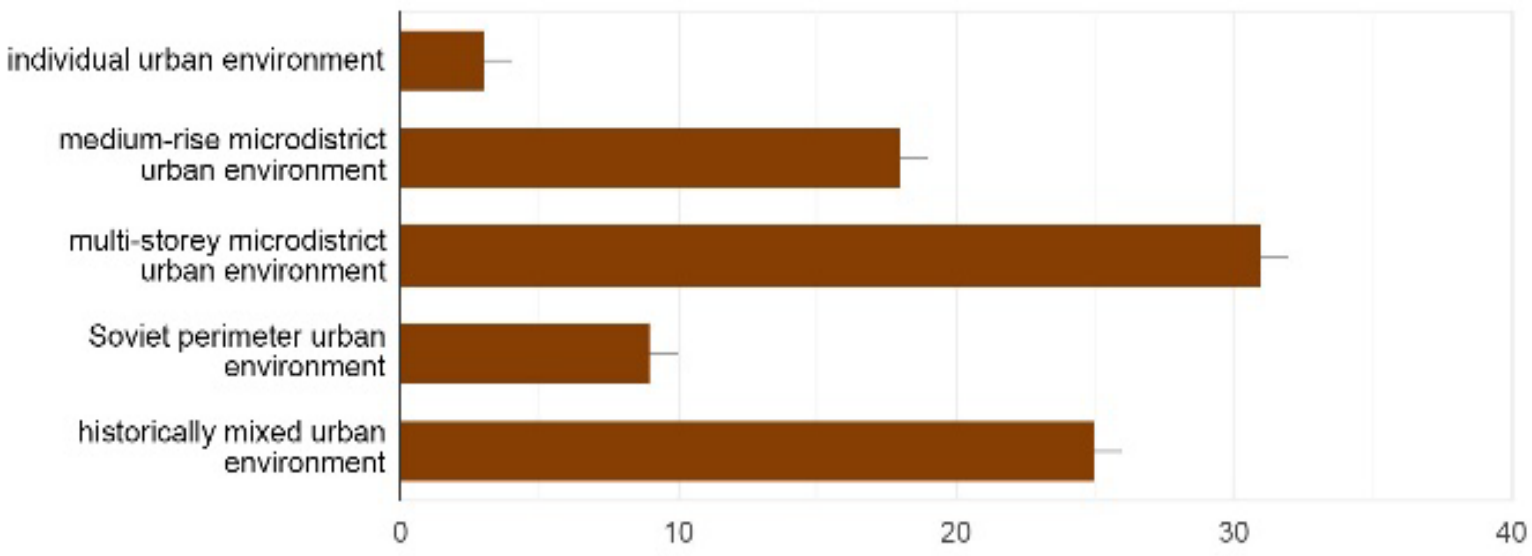

Figure 5. Diagram of the typology of the studied construction

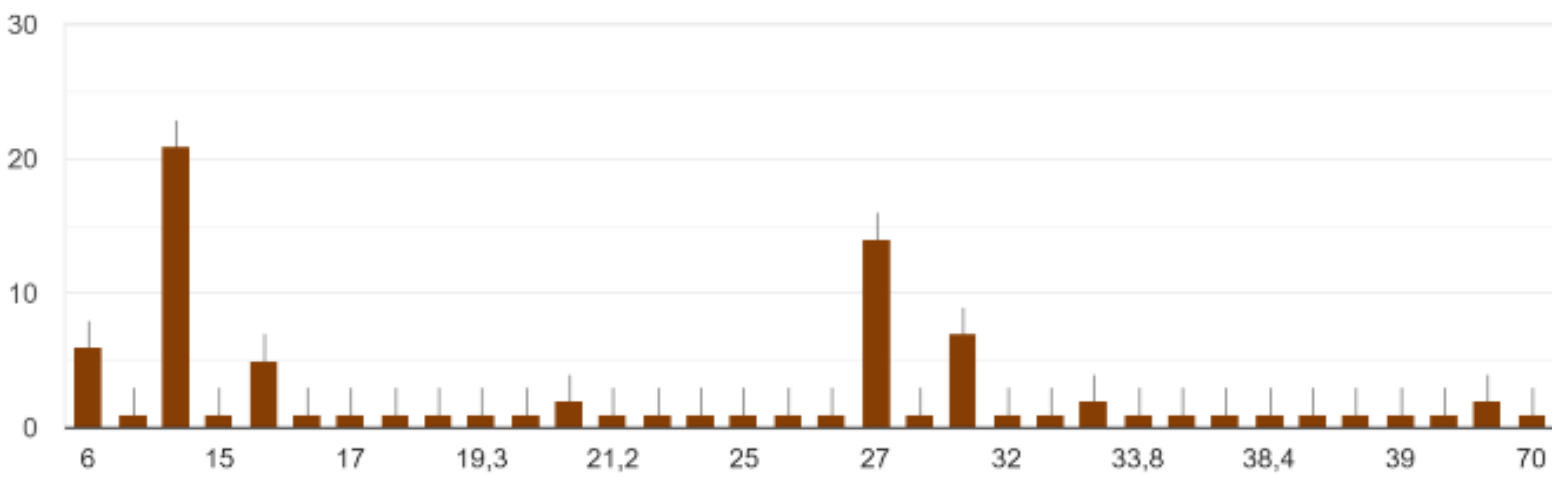

Figure 6. Diagram of the height of the studied construction 


\section{Acknowledgements}

The presented research was funded by Krasnoyarsk Regional Fund of Science in the framework of the scientific project "Modeling of the architectural structure and development of qualitative characteristics of the residential environment of Krasnoyarsk" (KF-773).

\section{REFERENCES}

[1] R. G. Arakelyan. Identification of traditional values of residential formations on the territory of the Armenian Highlands (Spatial planning solutions), Electronic journal "Architecture and modern architectural technologies (AMAT)", Vol.16, No.3, 2011.Online available from http://www.marhi.ru/AMIT/2011/3kvart11/arakelyan /abstract.php/.

[2] A. I. Rybak, I. B. Azarova. Quality assessment of the urban environment, Innovative economy and management in the modern world, 22-48, 2019.

[3] I. V. Matveeva, T. N. Luninina. Quality assessment for the territory environment of residential development for different periods of construction, Engineering systems and structures, No.22, 86-92, 2016.

[4] A. V. Dementieva, V. Yu. Domozhilov. Technical and economic criteria for assessing the quality of the urban environment in the renovation of residential buildings. Innovative economy: prospects for development and improvement, Vol.22, No.5, 22-26, 2017.

[5] M. V. Paskhina. Identification, typology and evaluation of urban morphotypes (on the example of Yaroslavl), Yaroslavl Pedagogical Bulletin, Vol.3, No. 4, 245-250, 2012.

[6] A.V. Kuzmin, G. S. Yusin. The quality of life and the quality of the spatial environment - social standards and norms in urban planning, Architecture, construction. Vol.14, No.4, 16, 2011

[7] G. I. Kuleshova, K. I. Sergeev. Ecologization of the urban environment: standards and directions of structural transformations / / Greening the urban environment: standards and directions of structural transformations, Moscow-Orel, 85-91, 2011.

[8] A. Grishina, N. V. Shilkin. Analysis of the rating system for evaluating NABUILD 2.35.4-2011 in the category of comfort and quality of the external environment, Buildings of High Technologies. No.2, 38-45, 2019.

[9] N. V. Bakaeva, A. Yu. Natarova, A. Yu. Igin. Criteria for assessing the environmental characteristics of residential and public buildings based on the concept of "green" construction, South-West state university, Vol.70, No.1,
57-68, 2017.

[10] S. V. Argunov, Yu. V. Kogan. System of criteria for assessing the urban development potential of residential areas of Moscow, Industrial and civil construction, No.6, 32-34, 2013.

[11] Methodological manual "Standard of integrated development of territories, Online available from https://cdn-arch strelka.gcdn.co/public_store/uploads/onlin e/readingcollection/7/file/original-e23129baceeb0956bf99 $86 \mathrm{~d} 5 \mathrm{~b} 34 \mathrm{fc} 9 \mathrm{e} 8 . \mathrm{pdf}$

[12] Rating of the quality of the residential environment. Rating methodology, Online available from http://urbanica.spb.ru/ wp-content/uploads/2016/11/Rejting-kachestva-zhiloj-sred y.pdf

[13] J. Gehl. Cities for people, Washington DC: Island Press, USA, 2010.

[14] N. N. Alddeen. Structural Assessment for Deteriorated Old Building Located in Bethlehem City, Palestine, Civil Engineering and Architecture, Vol.8, No.3, 246-257, 2020. DOI: $10.13189 /$ cea.2020.080307.

[15] F. Fornara, M. Bonaiuto, M. Bonnes.Cross-Validation of Abbreviated Perceived Residential Environment Quality (PREQ) and Neighborhood Attachment (NA) Indicators, Environment and Behavior, No.42, 171-196, 2010.

[16] M. Bonaiuto, F. Fornara, M. Bonnes.Indexes of Perceived Residential Innovative economics and management in the modern world, Environment Quality and Neighbourhood Attachment in Urban Environments: A Confirmation Study on the City of Rome. Landscape and Urban Planning, No.65, 41-52, 2003.

[17] M. Bonaiuto, F. Fornara, S. Ariccio, U. G. Cancellieri, L. Rahimi. Perceived Residential Environment Quality Indicators (PREQIs) Relevance for UN-HABITAT City Prosperity Index (CPI), Habitat International, No.45, 53-63, 2014.

[18] Husam R. Husain, H. Nafa. Socio-economic and Geo-political Transitions in the Mediterranean Basin and Its Impact on Urban Forms of Port Cities, Civil Engineering and Architecture, Vol.8, No.5, 898-907, 2020. DOI: 10.13189/cea.2020.080517.

[19] O. A. Shagaeva. New urbanization. The inevitability of the appearance of a new methodology for designing a quarter, Collection of materials of the International Conference of Students, Postgraduates and Young Scientists "Svobodnyy2015 Avenue", dedicated to the 70th anniversary of the Great Victory. Section "Urban planning", 76-79, 2015.

[20] S. F. Yamaletdinov. Ensemble of the Main Square in Krasnoyarsk-26: Humanized Space of Totalitarian Architecture, Journal of Siberian Federal University. Humanities \& Social Sciences, No.5, 742-755, 2021. 